\title{
Physical activity impact on motor development and oxidative stress biomarkers in school children with intellectual disability
}

\author{
Ahmad H. Alghadir \\ (iD) Sami A. Gabr
}

1. Rehabilitation Research Chair, College of Applied Medical Sciences, King Saud University, Riyadh, KSA

http://dx.doi.org/10.1590/1806-9282.66.5.600

\begin{abstract}
SUMMARY
OBJECTIVE: Lower physical fitness and poor motor performance were shown to be linked with higher levels of oxidative stress in children and adolescents with intellectual disabilities. Therefore, a moderate aerobic exercise for 12-weeks was performed to evaluate the effects of physical activity scores on motor functions, oxidative stress, and intelligence quotients (IQ) in school children with intellectual disability. METHODS: A total of 65 school children aged (12-18 Yrs) were randomly included in this study. Intellectual disability (ID), motor skills,physical fitness(VO2max), total energy expenditure (TEE), MDA, 8-OHdG, TAC, NO, and total oxidative stress(OS) were assessed using pre-validated WISC-IQ score test, BOT-2 test, PA questionnaire, and immunoassay techniques respectively.

RESULTS: WISC-IQ and BOT-2 set scores of intellectual and motor skills performance showed a significant correlation with physical activity status and the regulation of oxidative stress-free radicals in school children with mild and moderate ID following 12 weeks of moderate exercise. The intellectual and motor skills performance of the participants correlated positively with the increase in TAC activity and physical fitness scores and negatively with MDA, 8-OHdG, NO, and Total-OS, respectively. Stepwise multiple regression analysis of the demographic, physical status and oxidative stress parameters explained around78.0 to $93.4 \%$ of intellectual disability variation among schoolchildren.

CONCLUSION: Moderate aerobic training for 12 weeks has a positive impact on improving intellectual ability of schoolchildren with ID via modulating redox status, improves physical fitness, and motor skills proficiency.

KEYWORDS: Physical fitness. Exercise. Intellectual disability. Oxidative stress. Motor activity. Psychomotor performance.
\end{abstract}

\section{INTRODUCTION}

Active life styles and normal diets play a significant role in maintaining normal health for both children and adult populations via controlling obesity and nutritional related chronic disorders ${ }^{1,2}$.

Previous research studies reported that low levels of physical fitness and high rates of obesity were reported in individuals with intellectual disabilities (ID) ${ }^{3,4}$. These consequences promote health disturbances and increase the rates of morbidity and mortality among that populations ${ }^{3-5}$.

Most individuals with ID have functional and cognitive decline ${ }^{6}$, along with lower physical performance, less participation in social activities, and a sedentary lifestyle ${ }^{7}$.

The disturbance in oxidant -antioxidant status of biological cells may be related to several reasons

DATE OF SUBMISSION: 16-Nov-2019

DATE OF ACCEPTANCE: 25-Nov-2019

CORRESPONDING AUTHOR: Sami A. Gabr

Rehabilitation Research Chair, College of Applied Medical Sciences, King Saud University - P.O. Box 10219 - Riyadh 11433, KSA

Tel:+966562060018 - Fax: +96614698541

Email: dr.samigabr@gmail.com 
such as age-related diseases, metabolic disorders, sedentary lifestyle like poor physical activity, or mental stress as well as ID $^{7-11}$. Abnormal signaling levels of NO were significantly reported in a variety of neurodegenerative pathologies including intellectual disabilities ${ }^{12-14}$.

Also, 8-hydroxy-20-deoxyguanosine (8-OHdG) as oxidative biomarker was reported in the urine of individuals with severe motor and intellectual disabilities $(\mathrm{SMID})^{15}$. Similarly, a significant increase in the levels of malondialdehyde (MDA) as oxidative free radicals was reported in children with cerebral palsy, ID, and autism $^{13-17}$.

Motor development and brain functions in healthy children and adolescents were shown to be correlated with active physical performance in healthy and ID children or adolescents with lower or poor motor functions. ${ }^{2,18,19}$. This was significantly associated with a sedentary lifestyle or low physical activity ${ }^{20}$.

It was reported that participation of individuals with ID to programmed physical exercise interventions with varying intensities may have a positive impact results upon motor functions, ID scores, and quality of their life's ${ }^{2,15-17}$. However, the physiological and biochemical effects of physical exercise on the status of intellectual abilities among young individuals still have to be fully elucidated. Therefore, this study aims to evaluate the effects of 12-weeks of aerobic moderate exercise on motor functions and oxidative stress in school children with intellectual disability. In addition, we would like to see if there is any correlation between ID scores, motor function performance, and related oxidative stress biomarkers.

\section{METHODS}

\section{Participants}

A total of 85 school children aged (12-18 years) selected from different elementary and secondary public schools in Mansoura, Egypt between 2012 and 2013 randomly participated in this study. The sample size of 85 was selected from the list of students from different elementary and secondary public schools in a large geographical area of Mansoura to give estimate power of $95 \%$ and a significance level of 0.05 with expected frequency of $6.3 \%$. None of the selected participants have any physical disabilities to prevent them from participating in exercise programs. Based on the intelligence quotients (IQ), the participants were classified into three groups; normal healthy group (no=25; IQ =90-114); mild ID group (no=23; IQ=5070), and moderate ID group (no=37; IQ=35-49). Prior participation, written informed consent was obtained from all participants. The demographic and baseline data of participants were shown in Table 1.

\section{Exercise Program}

Participants were subjected to a supervised exercise program for 45-60 minutes three times per week for 12 weeks using treadmill ${ }^{10-13}$. This test provides the participants with maximum physical activities corresponding to $30 \%-45 \%$ of VO2 max uptake ${ }^{13}$. The maximum exercise of moderate- intensity (65\%-75\%) of each participant was calculated as training heart rate (THR) as previously reported ${ }^{18,19}$. Also, total energy expenditure (TEE) was evaluated by calculating basal metabolic rates (BMR) from body mass, height, age, sex, and type of physical activity of all participants using a pre-validated equation as previously reported $^{10,18,19}$.

\section{Intelligence Assessment}

A pre-validated Wechsler Intelligence Scale test was used to evaluate the intelligence quotients (IQ) of the participants before and after exercise interventions $^{15,16}$. IQ measurements of the participants were in the range of normal (IQ =90-114) mild (IQ=50-70), and moderate (IQ=35-49) respectively.

\section{Motor Assessment}

Motor skills among the participants were efficiently evaluated before and after exercise interventions by the use of pre-validated Bruininks-Oseretsky Test of Motor Proficiency, 2nd Edition (BOT-2. A test is a short form of 8 subtests with14 test items which has good validity and reliability to assist motor skill deficits among students aged 4-21 years ${ }^{16}$.

\section{Assessment of Oxidative Stress}

Estimation of total oxidative stress (OS)

The colorimetric test was evaluated to assess total oxidative stress (OS) from the fresh capillary blood of all participants by the use of CR 3000 instrument (free oxygen reactive measurement (FORM) system, Catellani Group, Callegari S.p.A, Parma, Italy). The principle of the test depends mainly on transition metals, such as iron catalyzes the breakdown of hydroperoxides into related active free radicals which measured at a wavelength $(\lambda ; 505 \mathrm{~nm})$ as shown previously ${ }^{2}$. 
TABLE 1. CHANGES IN DEMOGRAPHIC VARIABLES, PHYSICAL ACTIVITY, WISC-IQ, AND BOT-2 SCORES OF THE STUDIED SUBJECTS FOLLOWING 12-WEEKS OF SUPERVISED AEROBIC TRAINING INTERVENTIONS (N= 85; MEANS \pm SD).

\begin{tabular}{|c|c|c|c|c|c|c|}
\hline \multirow[t]{2}{*}{ Parameters } & \multicolumn{2}{|c|}{$\begin{array}{l}\text { Normal }(n=25 ; 29.4 \%) \\
(I Q=90-114)\end{array}$} & \multicolumn{2}{|c|}{$\begin{array}{l}\text { Mild ID }(n=23 ; 38.3 \%) \\
(I Q=50-70)\end{array}$} & \multicolumn{2}{|c|}{$\begin{array}{l}\text { Moderate ID }(n=37 ; 61.7 \%) \\
(I Q=35-49)\end{array}$} \\
\hline & Pre & Post & Pre & Post & Pre & Post \\
\hline Boys/Female & $20 / 5$ & $20 / 5$ & $18 / 5$ & $18 / 5$ & 20/17 & 20/17 \\
\hline Age (years) & $15.6 \pm 1.8$ & $15.6 \pm 1.8$ & $15.8 \pm 2.8$ & $15.8 \pm 2.8$ & $16.1 \pm 3.0$ & $16.1 \pm 3.0$ \\
\hline $\mathrm{BMI}\left(\mathrm{kg} / \mathrm{m}^{2}\right)$ & $21.6 \pm 3.5$ & $21.2 \pm 2.5^{\star}$ & $29.2 \pm 2.6$ & $22.6 \pm 1.8^{\star \star}$ & $31.6 \pm 1.5$ & $27.6 \pm 4.7^{\star \star}$ \\
\hline Waist (cm) & $78.5 \pm 8.3$ & $76.5 \pm 5.8^{*}$ & $103.9 \pm 12.5$ & $98.5 \pm 7.3^{\star *}$ & $108.5 \pm 3.8$ & $100 \pm 8.3^{\star *}$ \\
\hline Hips (cm) & $96.8 \pm 3.4$ & $92.6 \pm 3.8^{*}$ & $82.3 \pm 12.4$ & $76.9 \pm 3.2^{*}$ & $77.5 \pm 16.4$ & $74.9 \pm 3.9^{\star}$ \\
\hline WHR & $0.81 \pm 0.09$ & $0.78 \pm 0.12^{*}$ & $1.26 \pm 0.12$ & $0.96 \pm 0.14^{*}$ & $1.4 \pm 0.15$ & $1.1 \pm 0.16^{\star}$ \\
\hline Systolic BP (mmHg) & $126.5 \pm 3.6$ & $120 \pm 3.9^{*}$ & $115.6 \pm 12.3$ & $108 \pm 4.6^{*}$ & $120.3 \pm 5.7$ & $112 \pm 4.1^{\star}$ \\
\hline Diastolic BP (mmHg) & $72.8 \pm 12.4$ & $71.8 \pm 12.8$ & $87.5 \pm 7.6^{*}$ & $82.9 \pm 16.4^{\star}$ & $89.5 \pm 11.2$ & $87.9 \pm 15.4^{*}$ \\
\hline FBS (mg/dl) & $81.2 \pm 2.7$ & $78.6 \pm 3.2^{*}$ & $90.1 \pm 4.2$ & $86.6 \pm 3.6^{* *}$ & $98.1 \pm 3.5$ & $82.8 \pm 1.5^{\star \star}$ \\
\hline HbA1c (\%) & $2.5 \pm 0.15$ & $2.1 \pm 0.18^{*}$ & $2.9 \pm 1.2$ & $2.6 \pm 0.18^{*}$ & $3.1 \pm 0.96$ & $2.9 \pm 0.15^{\star \star}$ \\
\hline \multicolumn{7}{|l|}{ Physical activity (PA): } \\
\hline $\mathrm{VO}_{2} \max \left(\mathrm{ml} / \mathrm{kg}^{*} \min \right)$ & $38.7 \pm 6.1$ & $45.7 \pm 3.2^{\star *}$ & $21.6 \pm 1.8$ & $33.8 \pm 2.9^{\star \star}$ & $18.8 \pm 3.8$ & $28.2 \pm 5.3^{\star \star}$ \\
\hline BMR (kcal/day) & $2.95 \pm 3.65$ & $3.9 \pm 2.8^{*}$ & $1.73 \pm 2.54$ & $2.1 \pm 4.8^{\star \star}$ & $1.38 \pm 2.4$ & $3.5 \pm 5.4^{\star \star}$ \\
\hline TEE (kcal/day) & $4.59 \pm 6.4$ & $7.85 \pm 4.5^{\star}$ & $2.64 \pm 4.5$ & $4.65 \pm 3.5^{\star *}$ & $2.15 \pm 1.3$ & $4.35 \pm 5.8^{* \star}$ \\
\hline PA scores & $3.9 \pm 2.1$ & $5.8 \pm 2.5^{\star}$ & $1.96 \pm 1.3$ & $2.6 \pm 1.8^{* *}$ & $1.5 \pm 1.3$ & $2.9 \pm 1.4^{\star *}$ \\
\hline WISC- IQ test scores & $91.2 \pm 2.1$ & $102 \pm 3.7^{\star}$ & $51.3 \pm 3.7$ & $72.8 \pm 4.5^{\star \star}$ & $37.8 \pm 5.1$ & $58.2 \pm 6.5^{\star \star}$ \\
\hline \multicolumn{7}{|l|}{ BOT-2 test scores: } \\
\hline Fine motor precision & $35.7 \pm 3.5$ & $41.4 \pm 1.8^{*}$ & $21.4 \pm 8.0$ & $28.8 \pm 3.5^{\star \star}$ & $15.4 \pm 3.7$ & $21.8 \pm 3.6^{\star \star \star}$ \\
\hline Fine motor integration & $43.2 \pm 3.1$ & $58.4 \pm 2.98^{*}$ & $25.3 \pm 6.7$ & $31.5 \pm 3.9^{\star *}$ & $12.3 \pm 3.7$ & $18.1 \pm 2.6^{\star *}$ \\
\hline Manual dexterity & $30.5 \pm 2.7$ & $36.5 \pm 4.1^{*}$ & $10.5 \pm 3.4$ & $18.9 \pm 2.9^{*}$ & $8.7 \pm 2.4$ & $15.4 \pm 3.1^{*}$ \\
\hline Bilateral coordination & $11.8 \pm 1.85$ & $25.9 \pm 352^{*}$ & $13.4 \pm 1.8$ & $22.7 \pm 4.8^{\star \star}$ & $9.5 \pm 2.1$ & $16.7 \pm 4.6^{*}$ \\
\hline Balance & $29.3 \pm 2.6$ & $35.1 \pm 2.9^{*}$ & $18.9 \pm 4.7$ & $28.1 \pm 3.9^{\star \star}$ & $16.3 \pm 4.3$ & $24.1 \pm 3.5^{*}$ \\
\hline Running speed \& agility & $26.1 \pm 5.3$ & $35.1 \pm 3.1^{\star}$ & $16.5 \pm 2.9$ & $22.5 \pm 2.4^{\star \star}$ & $11.6 \pm 3.5$ & $17.5 \pm 3.5^{\star \star}$ \\
\hline Upper limb coordination & $23.7 \pm 2.4$ & $31.9 \pm 4.2^{*}$ & $15.7 \pm 5.3$ & $21.3 \pm 1.5^{\star *}$ & $12.3 \pm 2.5$ & $15.7 \pm 2.5^{\star \star}$ \\
\hline Strength & $10.6 \pm 6.3$ & $13.1 \pm 5.3^{*}$ & $9.7 \pm 4.7$ & $11.4 \pm 5.6^{\star \star}$ & $8.7 \pm 3.7$ & $16.2 \pm 4.5^{\star \star}$ \\
\hline Total Composite Score & $48.8 \pm 3.4$ & $56.6 \pm 5.8^{*}$ & $32.7 \pm 4.2$ & $39.8 \pm 3.4^{\star \star}$ & $23.6 \pm 3.5$ & $31.4 \pm 2.6^{\star \star}$ \\
\hline
\end{tabular}

Values are expressed as mean \pm SD; ${ }^{*} p<0.05,{ }^{* *} p<0.01,{ }^{* * *} p<0.001$. Significance at $p<0.05$. BMI: body mass index; WHR: waist to hip ratio; VO2 max: maximal oxygen uptake; FBS: fasting blood sugar; HbA1c: Glycated hemoglobin; BMR: basal metabolic rate (kcal/day); TEE: total energy expenditure (kcal/day); WISC- IQ: Wechsler Intelligence Scale test; BOT-2 test: Bruininks-Oseretsky Test of Motor Proficiency- Second Edition.

\section{Estimation of nitric oxide levels (NO)}

Nitric oxide (NO) concentrations were evaluated as nitrate and nitrite in all serum samples of the participants by the use of a Griess reagent as a chromophore agent. The developed color was estimated at a wavelength of $(\lambda ; 540 \mathrm{~nm})$ using high-performance liquid chromatography assay and the NO concentration was determined as previously reported $\mathrm{d}^{2,18-20}$.

Estimation of Malondialdehyde (MDA) and 8- $\mathrm{Hy}-$ droxyguanine (8-OHdG)

Malondialdehyde was estimated in the serum of the participants as a quantitative measure of lipid peroxidation using high-performance liquid chromatography as mentioned previously,18,19. Serum 8-OHdG as an oxidative biomarker of DNA damage was evaluated using immunoassay ELISA kit (DNA Damage ELISA Kit, Product \#: EKS-350, Stressgen Co., USA) as reported previously ${ }^{19}$.

\section{Estimation of total antioxidant capacity (TAC)}

Serum samples of all participants obtained preand post-exercise sessions were subjected for the estimation of total antioxidant capacity (TAC) by the use of colorimetric assay kit (K274-100; BioVision, Milpitas, CA, USA). The antioxidant activity was measured as a function of Trolox concentration at a wavelength of $(\lambda ; 570 \mathrm{~nm})$ as previously reported $^{18,19}$.

\section{Statistical Analysis}

The analyses of data were performed using SPSS version 17 and were expressed as mean \pm SD. Both student's-test and Pearson's correlation coefficient were used to investigating the comparison and correlation of the studied oxidative variables with ID and motor skills of all participants' pre-and post-exercise sessions. The data was significant at $P$ values $<0.05$. 


\section{RESULTS}

A total of 85 school children aged 12-18 years were randomly recruited in this study. Based upon WISCintelligence quotients (IQ) measurements, about 29.4 $\%$ of the participants ( $\mathrm{n}=25$ ) had normal IQ score of (90114) with mean $91.2 \pm 2.1$ WISC-IQ score, and $70.6 \%$ of the study population $(\mathrm{n}=60)$ diagnosed with intellectual disability; they were classified into mild IQ ( score 50-70) and moderate (score 35-49) as shown in table (1). A significant increase $(\mathrm{p}<0.01)$ in body mass index (BMI) and waist to hip ratio (WHR) and decrease $(\mathrm{p}<0.01)$ in VO2 max, BMR, and TEE were reported in participants with mild and moderate ID compared to other normally group. Also, significant improvement in adiposity markers; waist, hip, BMI, WHR, and sugar parameters (FBS and $\mathrm{HbA1c}(\%)$ were reported following interventions of supervised aerobic training (table 1).

The effects of supervised aerobic exercise on intellectual disability and total motor performance were reported in all participants. The data showed significant improvement in total WISC- IQ and BOT-2 test scores in schoolchildren with normal IQ $(p<0.05)$, and those with mild $(p<0.01)$, and moderate $(p<0.01)$ intellectual disability (ID) respectively following 12 weeks of aerobic training compared to pre-test baseline data (Table 1) and figure (1A).

The influence of supervised aerobic training on BOT-2 scores was significantly $(p<0.01)$ apparent in the improvement of specific areas of fine motor precision, running speed and agility, upper limb coordination, and strength while slightly moderate enhancement $(p<0.05)$ was detected for the specific areas of bilateral coordination, and balance (Table 1) and figure (1B)..

In this study, energy expenditure rates (EER), BMR, and VO2 max were evaluated as fitness scores among the participants. There was significantly improvement in the level of PA fitness scores among subjects with normal, mild, and moderate ID following 12 weeks of aerobic training compared to pre-test baseline data (Table 1) and figure (1C). Similarly, oxidative stress makers TAC, OS, MDA, NO, and 8-OHdG were assessed in this study. There was a significant reduction in the levels of OS, MDA, NO, 8-OHdG, and increase in the levels of TAC in normal $(p=0.05)$, mild $(p=0.01)$, and moderate ( $p=0.01)$ ID subjects following interventions of supervised aerobic training Figure (1D, 1E, and $1 \mathrm{~F})$.

Also, the data showed that the improvements in motor performance among participants with mild and moderate ID correlated positively with TAC, TEE, physical fitness scores, and negatively with BMI and other stress biomarkers, OS, MDA, NO, and 8-OHdG respectively (Table2). stepwise multiple regression analysis revealed that, Body mass index (BMI), age, gender, total BOT-2 scores, total oxidative stress, MDA, NO, and 8-OHdG concentrations, TEE, and PA fitness explained around 78.0 to $93.4 \%$ of intellectual disability variation among school children (Table 2).

\section{DISCUSSION}

Lower physical activity and sedentary lifestyles were reported among adolescents and children with intellectual disability (ID) than normal subjects ${ }^{1,2,6,7}$.

Although, the participation of subjects with ID in exercise interventions with different intensities which positively helps in improving of motor performance parameters, daily activities and quality of lif $\mathrm{e}^{18,21,22}$, still the effective role of oxidative stress on intellectual ability and its correlation with both exercise training and motor performance is not fully elucidated in school children which was our concern in this current study.

In the present study, intellectual ability among 65 school children aged 12-18 years was performed using WISC- IQ score. About 70.6\% of the study population $(n=60)$ diagnosed with intellectual disability;

TABLE2. BETA COEFFICIENTS AND CUMULATIVE $R^{2^{*}}$ VALUES DERIVED FROM STEPWISE MULTIPLE REGRESSION MODELS OF THE STUDIED DEMOGRAPHIC, PHYSICAL FITNESS, AND MOTOR PERFORMANCE SCORES (BOT-2 TEST) AMONG SCHOOL CHILDREN WITH ID ( $\mathrm{N}=60)$

\begin{tabular}{|c|c|c|}
\hline \multirow[t]{2}{*}{ Variables } & \multicolumn{2}{|c|}{$\begin{array}{l}\text { Intellectual disability (WISC- IQ score) } \\
\mathrm{n}=60\end{array}$} \\
\hline & $\begin{array}{l}\text { Mild }(n=23) \\
R^{2}(\beta)^{*}\end{array}$ & $\begin{array}{l}\text { Moderate }(n=37) \\
\mathrm{R}^{2}(\beta)^{*}\end{array}$ \\
\hline Age & $12.7(0.35)$ & $14.6(0.45)$ \\
\hline Gender & $4.8(0.16)$ & $6.7(0.28)$ \\
\hline $\mathrm{BMI}(\mathrm{kg} / \mathrm{m} 2)$ & $-5.1(0.18)$ & $-8.4(0.250)$ \\
\hline Total BOT-2 scores & $18.9(0.32)$ & $17.9(0.45)$ \\
\hline $\mathrm{OS}(\mathrm{mmol} / \mathrm{l} \mathrm{H} 2 \mathrm{O} 2)$ & $-4.9(0.12)$ & $-6.2(0.18)$ \\
\hline MDA (nmol/dl) & $-3.7(0.11)$ & $-5.2(0.14)$ \\
\hline $\mathrm{NO}(\mathrm{nmol} / \mathrm{dL})$ & $-5.9(0.14)$ & $-7.4(0.17)$ \\
\hline 8-OHG (ng/ml) & $-2.9(0.16)$ & $-4.1(0.21)$ \\
\hline TAC (nmol/ul) & $11.5(-0.22)$ & $12.9(-0.15)$ \\
\hline $\begin{array}{l}\text { Physical fitness } \\
\text { score (VO2 max) }\end{array}$ & $3.7(-0.38)$ & $5.8(-0.42)$ \\
\hline TEE(kcal/day) & $3.9(-0.17)$ & $4.2(-0.27)$ \\
\hline$\Sigma \mathrm{R} 2(\%)$ & $78 \%$ & $93.4 \%$ \\
\hline
\end{tabular}

Data presented as coefficient (R); ${ }^{*}$ significance at $p<0.01$; ${ }^{*}$ significance at $p<0.001$; BMI: body mass index; OS: total oxidative stress; MDA: Malondialdehyde; NO: nitric oxide; 8-OHdG: 8-Hydroxyguanine; TAC: total antioxidant capacity; VO2 max: maximal oxygen uptake; TEE: total energy expenditure (kcal/day). 
they were classified into mild IQ (score 50-70) and moderate (score 35-49). A significant increase (BMI) and (WHR) and decrease in VO2 max, BMR, and TEE were reported in participants with mild and moderate ID compared to the normal groups. Consistent to our study, others reported higher rates of obesity and lower performance in physical fitness scores among individuals with intellectual disability ${ }^{2-4,12-17}$. In the same line, a significant correlation was reported between BMI, gender, age, physical fitness scores with levels of intellectual disability ${ }^{20-22}$.

In the subjects with mild to moderate ID, oxidative stress-free radicals; T-OS, MDA, NO, 8-OHdG significantly increased and TAC activity significantly decreased. In support of our results, free radical oxidative stress was reported to play a pivotal role in most neurodegenerative brain disorders resulting from the side effects of drugs, lower physical activity, and poor $\operatorname{diet}^{2,7-17}$. Also, the severity of oxidative stress among participants with ID may be due to lack of physical activity, a mental disability which may be associated with free radicals oxidative cell damage and decrease in the antioxidants ${ }^{13-16,20,21 .}$

The decline in motor skills and brain functions were significantly reported in association with a lack of physical fitness in handling, precision of movements and motor activity ${ }^{2,18-24}$.

The current study reported that there was a significant decrease in motor skills among schoolchildren with mild and moderate ID. The data showed an agreement with others ${ }^{20-24}$, who reported a significant decline in both the intellect and the development of motor skills among children aged (7-12 years) with different mental retardation or disabilities. Also, the impairment in motor skills as measured by BOT-2 score test showed a significant correlation with higher

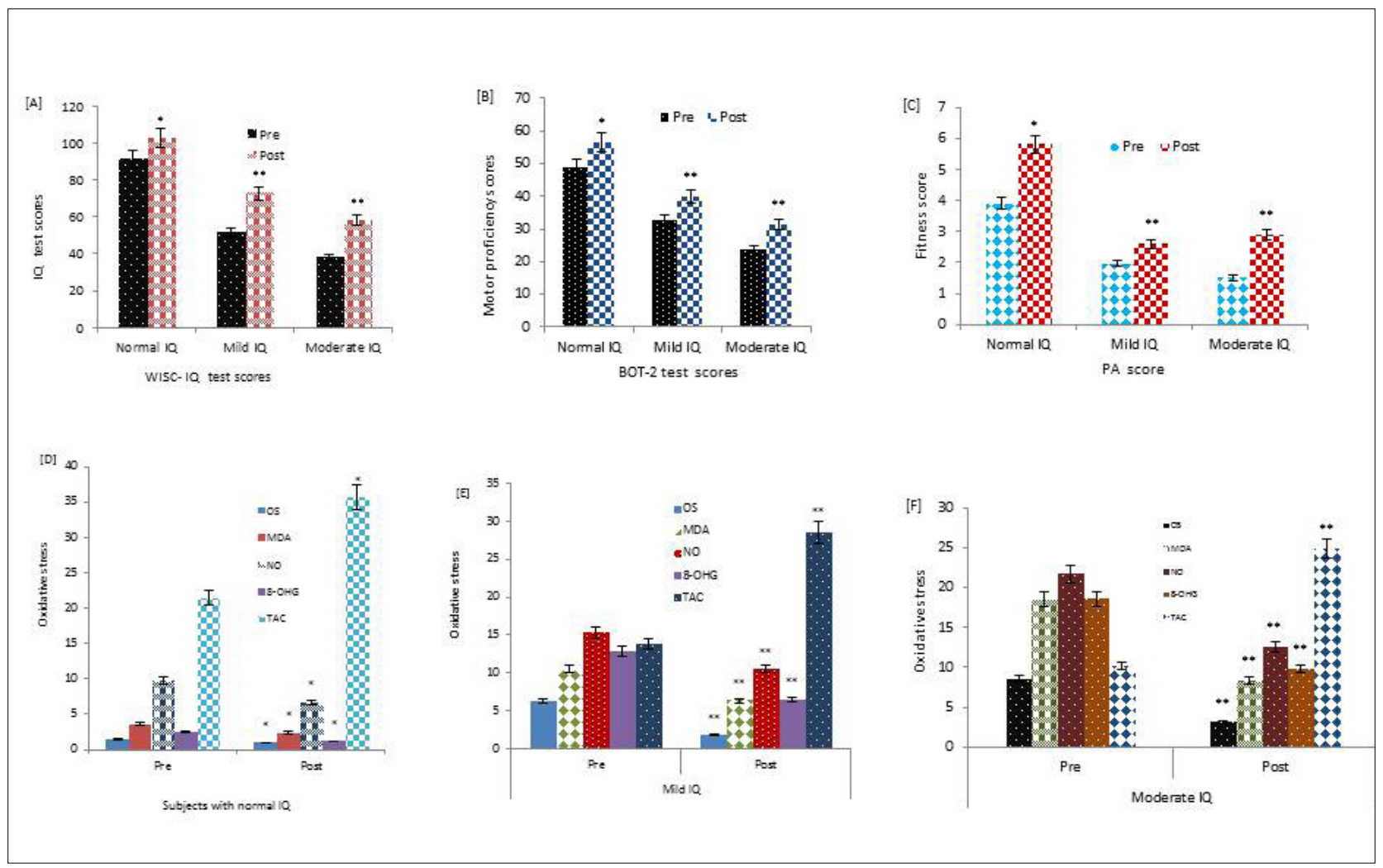

FIGURE 1: Changes in physical activity, of oxidative stress, WISC-IQ, and BOT-2 scores of the studied subjects following 12 -weeks of supervised aerobic training interventions ( $n=85$; means $\pm S D)$. In this study, there was significant improvement in IQ scores [A]; motor proficiency scores [B]; and fitness scores [C] in normal ( $p=0.05)$, mild ( $p=0.01)$, and moderate $(p=0.01)$ participants following 12-weeks of supervised aerobic training interventions. Similarly, there was significant reduction in the levels of OS, MDA, NO, 8-OHdG, and increase in the levels of TAC in normal ( $p=0.05)$, mild ( $p=0.01)$, and moderate ( $p=0.01)$ IQ subjects flowing interventions of supervised aerobic training.

Values are expressed as mean \pm SD; ${ }^{*} p<0.05,{ }^{* *} p<0.01,{ }^{\star \star *} p<0.001$. WISC- IQ: Wechsler Intelligence Scale test; BOT-2 test: Bruininks-Oseretsky Test of Motor Proficiency- Second Edition; OS: total oxidative stress; MDA: Malondialdehyde; NO: nitric oxide; 8-OHdG: 8-Hydroxyguanine; TAC: total antioxidant capacity; TEE: total energy expenditure (kcal/day); VO2 max: maximal oxygen uptake. Significance at $\mathrm{p}<0.05$ 
values of adiposity markers; BMI, WHR, oxidative stress parameters, and lower physical fitness scores in schoolchildren with mild and moderate ID compared with a control group of standard IQ which consistently supported previously ${ }^{12,17,22}$.

Previous research studies showed improvement in physical activity such as balance, strength, endurance and health self-perception along with a decrease in adiposity markers among participants with mild disability following participation in exercise programs ${ }^{20-24}$.

However, rare data were found about supervised aerobic exercise programs and their influence on oxidative stress, motor skills, and IQ scores among schoolchildren with ID. So, the present study investigated the effects of 12-week aerobic training of moderate-intensity on ID, physical activity, motor skills, and oxidative stress in schoolchildren. The data obtained showed a significant improvement in intellectual abilities as measured by WISC- IQ score of all participants with mild and moderate ID following 12-week of moderate exercise interventions. Also, the influence of exercise was observed in the improvements of motor skills (BOT-2 scores), increase in TAC, physical fitness, and a reduction in all oxidative stress-free radicals; OS, MDA, NO, and 8-OHdG in all participants following exercise interventions for 12- weeks.

Previously, it was reported that targeted physical exercise programs significantly affects on physical fitness and enhance of IQ scores among children with ID ${ }^{2,18-21}$. Also, 10-week aerobic exercise interventions were shown to have positive beneficial effects on physical fitness score, exercise capacity, IQ scores, and an increment in maximum oxygen uptake (VO2 max) ${ }^{21-23}$.

Finally, our study showed that motor skills (BOT-2) and IQ scores correlated positively with BMI, WHR, physical fitness, TAC, TEE variables, and negatively with oxidative markers OS, MDA, NO, and 8-OHdG. Also, motor skills such as motor precision, running speed, agility, upper limb coordination, strength, bilateral coordination, and balance were significantly improved in school children following 12-week of aerobic exercise. The data matched with recent research works which reported a significant link between motor skills and brain function developments with active physical performance ${ }^{2,12-17}$, and that moderate aerobic exercise has a positive antioxidant effect on brain disorders via modulating the release of oxidative stress biomarkers ${ }^{3-5,21-24}$. Finally, stepwise multiple regression analysis of these parameters along with age and gender explained around 78.0 to $93.4 \%$ of intellectual disability variation among school children.

The results of this study strengthen and signifying enclosure of physical exercise interventions, particularly those of a supervised training program to improve intellectual ability via improving physical fitness, motor skills proficiency and modulating redox status. In addition modulating redox status might be considered as diagnostic non-invasive predictors of intellectual abilities for clinical use in epidemiological contexts; however, further studies with larger sample size and studying gender influence are significantly required.

In conclusion, moderate aerobic training for 12 weeks has a positive impact on improving intellectual ability via improving physical fitness, motor skills proficiency, and modulating redox status of schoolchildren with intellectual disability.

\section{Ethics approval and consent to participate}

Based on the ethical guidelines of the 1975 Declaration of Helsinki, the study protocol was reviewed and approved by ethical committee of Rehabilitation Research Chair (RRC), King Saud University, Kingdom of Saudi Arabia, under file number ID: RRC-2014-014. Prior to data collection, written informed consent was obtained from the parents of all participating schoolchildren

\section{Authors' Contributions}

Research idea, design, and practical work were proposed by GSA. Review of literature was done by AHA. GSA executed data collection and analysis. Manuscript preparation and submission was done by GSA.

\section{Acknowledgement/Funding}

The authors are grateful to the Deanship of Scientific Research, King Saud University for funding through Vice Deanship of Scientific Research Chairs

\section{Competing interests:}

The authors declare that they have no competing interests. 


\section{RESUMO}

OBJETIVO: A baixa aptidão física e o baixo desempenho motor mostraram-se associados a níveis mais altos de estresse oxidativo em crianças e adolescentes com deficiência intelectual. Portanto, foi realizado um exercício aeróbico moderado por 12 semanas para avaliar os efeitos dos escores de atividade física nas funções motoras, estresse oxidativo e quocientes de inteligência (QI) em escolares com deficiência intelectual.

MÉTODOS: Um total de 65 crianças em idade escolar (12 a 18 anos) foi incluído aleatoriamente neste estudo. A incapacidade intelectual (DI), habilidades motoras, aptidão física (VO2máx), gasto energético total (ETE), MDA, 8-OHdG, TAC, NO e estresse oxidativo total (SG) foram avaliados pelo teste de pontuação Wisc-IQ pré-validado, teste BOT-2, questionário de PA e técnicas de imunoensaio, respectivamente.

RESULTADOS: Os escores do conjunto Wisc-IQ e BOT-2 do desempenho das habilidades intelectuais e motoras mostraram uma correlação significativa com o status da atividade física e a regulação dos radicais livres do estresse oxidativo em escolares com DI leve e moderada após 12 semanas de exercício moderado. O desempenho das habilidades intelectuais e motoras dos participantes correlacionou-se positivamente com o aumento dos escores de atividade TAC e aptidão física e negativamente com MDA, 8-OHdG, NO e Total-OS, respectivamente. Houve uma melhora significativa nas habilidades motoras, como áreas específicas de precisão motora fina, velocidade de corrida, agilidade, coordenação de membros superiores, força, coordenação bilateral e equilíbrio entre crianças em idade escolar após o programa de exercícios. A análise de regressão múltipla passo a passo dos parâmetros demográficos, do estado físico e do estresse oxidativo explicou em torno de 78,0 a 93,4\% da variação da incapacidade intelectual entre os escolares.

CONCLUSÃO: O treinamento aeróbico moderado por 12 semanas tem um impacto positivo na melhoria da capacidade intelectual de escolares com DI por meio da modulação do status redox, melhora da aptidão física e proficiência em habilidades motoras.

PALAVRAS-ChaVE: Aptidão física. Exercício. Deficiência intelectual. Estresse oxidativo. Atividade motora. Desempenho psicomotor.

\section{REFERENCES}

1. Kilgour $A H$, Starr JM, Whalley LI. Associations between childhood intelligence (IQ), adult morbidity and mortality. Maturitas. 2010;65(2):98-105.

2. Carmeli E, Imam B, Bachar A, Merrick J. Inflammation and oxidative stress as biomarkers of premature aging in persons with intellectual disability. Res Dev Disabil. 2012;33(2):369-75.

3. Lima-Cabello E, Garcia-Guirado F, Calvo-Medina R, el Bekay R, Perez-Costillas L, Quintero-Navarro C, et al. An abnormal nitric oxide metabolism contributes to brain oxidative stress in the mouse model for the fragile $X$ syndrome, a possible role in intellectual disability. Oxid Med Cell Longev. 2016;2016:8548910.

4. Michel T, Vanhoutte PM. Cellular signaling and NO production. Pflugers Arch. 2010;459(6):807-16.

5. Frackowiak I, Mazur-Kolecka B, Schanen NC, Brown WT, Wegiel I. The link between intraneuronal $\mathrm{N}$-truncated amyloid - peptide and oxidatively modified lipids in idiopathic autism and dup (15q11.2-q13)/autism. Acta Neuropathol Commun. 2013;1:61.

6. Lam HMY. Assessment of preschoolers' gross motor proficiency: revisiting Bruininks-Oseretsky Test of Motor Proficiency. Early Child Development and Care. 2011;181(2):189-201.

7. Abdullah B, Jaafar WMW, Ayub AFM. The development of gross motor analysis system software: a preliminary concept. Procedia- Social and Behavioral Sciences. 2012;64:501-6.

8. Aaltonen S, Latvala A, Rose RJ, Pulkkinen L, Kujala UM, Kaprio J, et al. Motor development and physical activity: a longitudinal discordant twin-pair study. Med Sci Sports Exerc. 2015;47(10):2111-8.

9. Pitetti KH, Beets MW, Combs C. Physical activity levels of children with intellectual disabilities during school. Med Sci Sports Exerc. 2009;41(8):1580-6.

10. Westendorp M, Houwen S, Hartman E, Visscher C. Are gross motor skills and sports participation related in children with intellectual disabilities? Res Dev Disabil. 2011;32(3):1147-53

11. Aouadi R, Nawi Alanazi HM, Tim G. Impact of physical exercise on reactive time and cognitive function in mentally deficient adolescents. I Clin Trials. 2015;5(1):206

12. Lista I, Sorrentino G. Biological mechanisms of physical activity in preventing cognitive decline. Cell Mol Neurobiol. 2010;30(4):493-503.

13. Krick J, Murphy PE, Markham JF, Shapiro BK. A proposed formula for calculating energy needs of children with cerebral palsy. Dev Med Child Neurol. 1992;34(6):481-7.

14. Fleisch $A$. Basal metabolism standard and its determination with the "metabocalculator". Helv Med Acta. 1951;18(1):23-44.

15. Canivez $G$, Watkins $M$. Exploratory and higher-order factor analyses of the Wechsler Adult Intelligence Scale-Fourth Edition (WAIS-IV) adolescent subsample. School Psychology Quarterly. 2010;25(4):223-5.

16. Wechsler D. WAIS-IV: administration and scoring manual. Minneapolis: NCS Pearson Inc.; 2008.

17. Bruininks RH, Bruininks BD. Bruininks-Oseretsky test of motor proficiency. $2^{\text {nd }}$ ed. Windsor: NFER-Nelson; 2005.

18. Carmeli E, Imam B, Bachar A, Merrick J. Inflammation and oxidative stress as biomarkers of premature aging in persons with intellectual disability. Res Dev Disabil. 2012;33(2):369-75.

19. Alghadir AH, Gabr SA, Al-Eisa ES. Effects of moderate aerobic exercise on cognitive abilities and redox state biomarkers in older adults. Oxid Med Cell Longev. 2016;2016:2545168.

20. Alghadir AH, Gabr SA, Anwer S, Al-Eisa E. Fatigue and oxidative stress response to physical activity in type 2 diabetic patients. Int | Diabetes Dev Ctries. 2016;36:59-64

21. Top $E$. The effect of swimming exercise on motor development level in adolescents with intellectual disabilities. Am J Sports Science Med. 2015;3(5):85-9.

22. Lotan M, Isakov E, Kessel S, Merrick J. Physical fitness and functional ability of children with intellectual disability: effects of a short-term daily treadmill intervention. Scientific World J. 2004;4:449-57.

23. Wu CL, Lin JD, Hu J, Yen CF, Yen CT, Chou Y L, et al. The effectiveness of healthy physical fitness programs on people with intellectual disabilities living in a disability institution: six-month short-term effect. Res Dev Disabil. 2010;31(3):713-7.

24. Golubović Š, Maksimović |, Golubović B, Glumbić N. Effects of exercise on physical fitness in children with intellectual disability. Res Dev Disabil. 2012;33(2):608-14.

25. Khalili MA, Elkins MR. Aerobic exercise improves lung function in children with intellectual disability: a randomised trial. Aust Physiother. 2009;55(3):171-5. 